This item was submitted to Loughborough's Research Repository by the author.

Items in Figshare are protected by copyright, with all rights reserved, unless otherwise indicated.

\title{
Effects of playing surface on physical, physiological and perceptual responses to a repeated sprint ability test: natural grass versus artificial turf
}

\section{PLEASE CITE THE PUBLISHED VERSION}

https://doi.org/10.1123/ijspp.2018-0766

\section{PUBLISHER}

(C) Human Kinetics

\section{VERSION}

AM (Accepted Manuscript)

\section{PUBLISHER STATEMENT}

This work is made available according to the conditions of the Creative Commons Attribution-NonCommercialNoDerivatives 4.0 International (CC BY-NC-ND 4.0) licence. Full details of this licence are available at: https://creativecommons.org/licenses/by-nc-nd/4.0/

\section{LICENCE}

CC BY-NC-ND 4.0

\section{REPOSITORY RECORD}

Ammar, Achraf, Stephen Bailey, Omar Hammouda, Khaled Trabelsi, Nabil Merzigui, Kais El Abed, Tarak Driss, et al.. 2019. "Effects of Playing Surface on Physical, Physiological and Perceptual Responses to a Repeated Sprint Ability Test: Natural Grass Versus Artificial Turf". figshare. https://hdl.handle.net/2134/36931. 


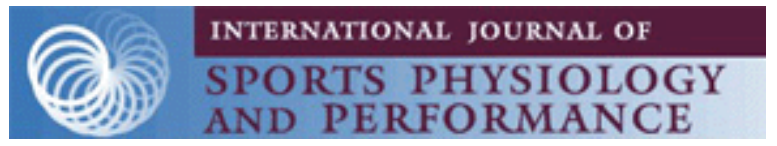

\section{Effects of playing surface on physical, physiological and perceptual responses to a repeated sprint ability test: natural grass versus artificial turf}

\begin{tabular}{|c|c|}
\hline Journal: & International Journal of Sports Physiology and Performance \\
\hline Manuscript ID & IJSPP.2018-0766.R1 \\
\hline Manuscript Type: & Original Investigation \\
\hline $\begin{array}{r}\text { Date Submitted by the } \\
\text { Author: }\end{array}$ & $\mathrm{n} / \mathrm{a}$ \\
\hline Complete List of Authors: & $\begin{array}{l}\text { Ammar, Achraf; High Institute of Sport and Physical Education of Sfax, } \\
\text { Université of Sfax, Sfax, Tunisia; Institute of Sport Science, Otto-von- } \\
\text { Guericke-University, Magdeburg, Germany., } \\
\text { Bailey, Stephen; Loughborough University, School of Sport, Exercise and } \\
\text { Health Sciences } \\
\text { Hammouda, Omar; High Institute of Sport and Physical Education of } \\
\text { Sfax, Université of Sfax, Sfax, Tunisia sfax } \\
\text { Trabelsi, Khaled; High Institute of Sport and Physical Education of Sfax, } \\
\text { Université of Sfax, Sfax, Tunisia sfax } \\
\text { Merzigui, Nabil; High Institute of Sport and Physical Education of Sfax, } \\
\text { Université of Sfax, Sfax, Tunisia sfax } \\
\text { El Abed, Kais; Faculty of Medicine Ibn El Jazzar, Sousse, Tunisia, } \\
\text { Laboratory of Cardio-Circulatory, Respiratory, Metabolic and Hormonal } \\
\text { Adaptations to Muscular Exercise } \\
\text { Driss, Tarak; Research Center on Sport and Movement (EA 2931), } \\
\text { University of Paris Nanterre, Nanterre, France } \\
\text { Hoekelmann, Anita } \\
\text { Ayedi, Fatma; 1Laboratory of Biochemistry, CHU Habib Bourguiba, Sfax } \\
\text { University, Sfax, Tunisia } \\
\text { Chtourou, Hamdi; High Institute of Sport and Physical Education of Sfax, } \\
\text { Université of Sfax, Sfax, Tunisia sfax } \\
\text { Gharbi, Adnen; High Institute of Sport and Physical Education of Sfax, } \\
\text { Université of Sfax, Sfax, Tunisia sfax } \\
\text { Turki, Mouna; 1Laboratory of Biochemistry, CHU Habib Bourguiba, Sfax } \\
\text { University, Sfax, Tunisia }\end{array}$ \\
\hline Keywords: & Soccer, Biochemical, sport, Fatigue \\
\hline
\end{tabular}

\section{SCHOLARONE ${ }^{\text {TM }}$ Manuscripts}


Effects of playing surface on physical, physiological and perceptual responses to a performance, fatigue perception and blood markers of inflammation, muscle damage and immune function duringrepeated sprint ability test: natural grass versus artificial turf

Submission Type: Original Investigation

\section{Author names:}

Achraf Ammar ${ }^{1,2}$, Stephen J. Bailey ${ }^{3}$, Omar Hammouda ${ }^{4}$, Khaled Trabelsi ${ }^{4}$, Nabil Merzigui ${ }^{4}$, Kais El Abed ${ }^{4}$, Tarak Driss ${ }^{5}$, Anita Hoekelmann² ${ }^{2}$ Fatma Ayadi ${ }^{1}$, Hamdi Chtourou ${ }^{4}$, Adnen Gharbi $^{4}$, Mouna Turki ${ }^{1}$

${ }^{1}$ Laboratory of Biochemistry, CHU Habib Bourguiba, Sfax University, Sfax, Tunisia ${ }^{2}$ Institute of sport science, Otto-von-Guericke University, Magdeburg, Germany ${ }^{3}$ School of Sport, Exercise and Health Sciences, Loughborough University, Loughborough, United Kingdom

${ }^{4}$ High Institute of Sport and Physical Education of Sfax, Sfax University, Sfax, Tunisia ${ }^{5}$ Research Center on Sport and Movement (EA 2931), University of Paris Nanterre, Nanterre, France

*Corresponding author: Achraf Ammar.

Address: High Institute of Sport and Physical Education, Road Aeroport, Km 3,5, BP 384, Sfax 3000, Tunisia.

E-mail:ammar.achraf@ymail.com Phone number : 0021620420326

orcid.org/0000-0003-0347-8053

Running Head: Effects of playing surface on RSA performance Abstract word count: 248

Text word count: 2964

Number of figures and tables: 5 figures 
1 Effects of playing surface on physical, physiological and perceptual responses to a performance, fatigue perception and blood markers of inflammation, muscle damage

3 and immune function duringrepeated sprint ability test: natural grass versus artificial

4 turf

5

6

7

8

9

10

11

12

13

14

15

16

17

18

19

20

21

22

1

Human Kinetics, 1607 N Market St, Champaign, IL 61825 


\section{Abstract}

Purpose: The effect of playing surface on physical performance during a repeated sprint ability (RSA) test, and the mechanisms for any potential playing-surface-dependent effects on RSA performance, is equivocal. The purpose of this study was to investigate the effect of natural grass $(\mathrm{NG})$ and artificial turf (AT) on physical performance, ratings of perceived exertion (RPE), feeling scale (FS) and blood biomarkers related to fatigueanaerobic contribution [lactate (Lac)], muscle damage [creatine kinase $(\mathrm{CK})$ and lactate dehydrogenase $(\mathrm{LDH})$ ], inflammation [c-reactive protein (CRP)] and immune function [neutrophils (NEU), lymphocytes (LYM) and monocytes (MON)] in response to a RSA test. Methods: Nine male professional football players from the same regional team were randomly assigned to completed two sessions of RSA testing ( $6 \times 30 \mathrm{~s}$ interspersed by $35 \mathrm{~s}$ recovery) on NG and AT in a randomized order. During the RSA test, total (sum of distances) and peak (highest distance covered in a single repetition) distance covered were determined using a measuring tape and the decrement in sprinting performance from the first to the last repetition was calculated. and covered, best performance and performance decrementin sprinting performance, Before and after the RSA test, RPE, FS, and blood [Lac], [CK], [LDH], [CRP], [NEU], [LYM] and [MON] were recorded in both NG and AT conditions. Results: Although physical performance declined during the RSA sprint blocks on both surfaces $(p=0.001)$, the distance covered declined more on NG $(15 \%)$ compared to AT $[11 \% ; \mathrm{p}=0.04$, ES $=-0.34,95 \%$ CI $(-1.21,0.56)]$ with a higher total distance covered $(+6 \pm 2 \%)$ on AT $[\mathrm{p}=0.018, \mathrm{ES}=1.15$, 95\% CI $(0.16,2.04)]$. In addition, This improved RSA on AT compared to NG was acempanied by-lower RPE $[\mathrm{p}=0.04$, ES $=-0.49,95 \%$ CI $(-1.36,0.42)]$ and blood [Lac], $[\mathrm{NEU}]$ and $[\mathrm{LYM}][\mathrm{p}=0.03 ; \mathrm{ES}=-0.80,95 \% \mathrm{CI}(-1.67,0.14) ; \mathrm{ES}=-0.16,95 \% \mathrm{CI}(-1.03,0.72)$ and $\mathrm{ES}=-0.94,95 \% \mathrm{CI}(-1.82,0.02)$, respectively) $]$ and more positive feelings $[\mathrm{p}=0.02$, $\mathrm{ES}=0.81,95 \% \mathrm{CI}(-0.13,1.69)]$ were observed following the RSA test performed on AT 
compared to NG. No differences were observed in the remaining physical and blood markers. There were no between playing surface differences in the other blood biomarkers $(p>0.05)$.

Conclusion: These findings suggest that RSA performance is enhanced on AT compared to NG. This effect was-is enhanced on AT compared to NG, an effect thatis-accompanied by

52 lower fatigue perception and blood [Lac], [NEU] and [LYM], and a more pleasurable feeling.

53 These observations might have implications for physical performance in intermittent team 54 sports athletes who train and compete on different playing surfaces.

55 Keywords: Soccer; Biochemical; Sport; Fatigue. 


\section{Introduction}

It is widely accepted that the performance of in football (soccer) players-is not solely affected by internal factors such as the their age, fitness status and cognitive abilities of the players. ${ }^{1,2}$ physical and cognitive abilities, but also by external factors. ${ }^{t}$ such as In addition, environmental factors, including the playing context eharacteristies of the ball and, shoes characteristics and playing surface with whichtheythe player interact have been identified as important external factors that can influence football performance..$^{2-4}$ In 2005 , the use of the third $3^{\text {rd }}$ generation $(3 G)$ artificial turf (AT) was officially approved by the Union of European Football Associations (UEFA) and the International Federation of Association Football (FIFA) as an alternative to natural grass tournaments. ${ }^{5}$ Since this official approval, use of AT has increased exponentially for both training and competition efficial football games or for training. ${ }^{6-8}$ Accordingly, this has resulted in-an increased-increasing number of research studies being-have been conducted to assess the influence of playing surface on various technical and physical components of football performance and injury risk. ${ }^{9-11}$

To date, studies assessing the influence of playing surface type on physical performance abilities have yielded conflicting results. During competitive games, Andersson et al. ${ }^{10}$ observed similar running (e.g., sprint number, high-intensity running and total covered distance) and technical (e.g., standing tackles) patterns on AT compared to NG. Moreover, single sprint performance, ${ }^{11}$ as well as jumping and agility performances ${ }^{12,13}$ appear to be similar on AT and NG during a soccer-simulation protocol. On the other hand, the effect of playing surface on repeated sprint ability (RSA), on the other hand is equivocal. ${ }^{13,14}$ However, pPlaying surface has been shown to influence some variables, such as the peak and average speed, ${ }^{15}$ the playing style ${ }_{\overline{5}}{ }^{10}$ and the change of direction ability ${ }_{\overline{5}}^{11,12,14}$ with players also exhibiting better technical skills (e.g., fewer sliding tackles, more short passes and faster 
turns and direction change abilities) on AT compared to NG. These findings suggest that exercise tasks that require more direction changes might be more likely to observe a beneficial effect on AT compared to NG. However, the physiological and perceptual bases of these potential surface-dependent effects on physical and technical components of football performance are poorly defined.

Empirical research studies assessing physiological responses to exercise performed on AT compared to NG have yielded inconsistent findings. ${ }^{3}$ Although, higher blood lactate (Lac) values at given heart rate $(\mathrm{HR})$ have been observed during an incremental running test performed on AT compared to NG, ${ }^{16}$ it has also been reported that heart rate (HR), Lac accumulation, as well as the and the metabolic cost of running were not different during a football match simulation and constant-speed running en between NG and AT. ${ }^{12,17}$ Stone et al. ${ }^{13}$ were the first to assess the muscle damage response to 90 min soccer-simulation protocol (SSP) played on AT and NG and reported that blood creatine kinase (CK) concentration was similar for both surfaces immediately and up to 48 hours post-test. Since CK is just one indicator of muscle damage and two or more biomarkers are recommended to accurately infer muscle damage, ${ }^{18}$ further studies using multiple biomarkers (e.g., CK and lactate dehydrogenase (LDH) $)^{19,20}$ are required to robustly address the influence of surface-type on muscle damage responses following physical exercise. Moreover, the effect of playing surface on biomarkers of immune response [e.g., neutrophils (NEU), monocytes (MON), and lymphocytes (LYM)], ${ }^{21,22}$ inflammation [e.g., C-reactive protein (CRP)], ${ }^{23,24}$ metabolism (e.g., Lac and glucose (GLC)), ${ }^{25}$ and perceptual responses during exercise has yet to be investigated.

Given that the effects of playing surface on muscle damage, and inflammatory and immune responses to physical exercise is poorly defined, and given the discrepancy in the existing literature assessing the effect of playing surface on physical performance, the purpose of this 
study was to assess the effect of AT compared to vs. NG on physical performance and perceptual and physiological responses to responses in-a multiple direction change RSA test in football players. It was hypothesized that RSA performance would be enhanced on AT compared to NG concomitant with lower physiological and perceptual strain. Moreover, since previous studies suggest that physical performance can be enhanced when muscle damage and inflammatory responses to exercise are attenuated, ${ }^{13,26,27}$ it was also hypothesized that enhanced RSA performance on AT would be accompanied by reduced acute physiological stress responses.

\section{Methods}

\section{SubjectsParticipants}

Nine male professional football players (mean \pm SD age: $21.8 \pm 1.1$ years, body mass: $69.4 \pm$ $9.8 \mathrm{~kg}$, statureheight: $1.78 \pm 0.62 \mathrm{~m}$, body fat: $11.4 \pm 2.5 \%$ ) from the same regional team volunteered to participate in this study. All subjects participantshad had at least five years of experience in practicing as a football player-and they usually trained at least three to four days per week for an average of $2 \mathrm{~h}$ per day daily. To ensure an objective evaluation of the AT and to avoid any effect of adaptations, ${ }^{28}$ subjectsparticipants were not accustomed to regularly training or playing on $3^{\text {rd }}$ generation $3 G$ AT. None of the subjects participantshad had any knownprevious injury or cardiopulmonary disease and they did not ingest any antioxidant compounds or medications (e.g., anti-inflammatory agents) for six months prior to, or during, $\Theta$ r six months prior to, the start of the study. After receiving a thorough explanation of the possible risks and discomforts associated with the experimental procedures, subjectsparticipants provided written informed consent to participate in the study. The experimental procedures of the present study were approved by the University's Ethics Committee and conformed to the last version of the Helsinki Declaration.

\section{Design}


Following an initial familiarization session, subjectsparticipants performed two test sessions in a randomized order on AT ( $3 G$ surface)and NG which had achieved a "FIFA 1 Star" rating. A period of $72 \mathrm{~h}$ separated the different test sessions to ensure the-full recovery of the for each players. ${ }^{7}$ Test sessions were conducted in the afternoon hours-(15:00-16:30) since this timeframe has been reported to coincide with optimal physiological responses and maximum levels of power output during different forms of physical exercise tests. ${ }^{20,26,27}$ Players reported to the test-football pitches at 14:00 to record and had their body mass (Tanita, Tokyo, Japan) and height recorded-(Secastadiometer, Germany) during their first session. Before starting the physical test, subjectsparticipants performed a standard pre-test warm-up consisting of 5 min of continuous running, $5 \mathrm{~min}$ of articulation mobility exercises and three sprints of $30 \mathrm{~m}$ of increasing intensity interspersed by, with a 2 min recovery between each test. ${ }^{7}$ Upon completion of the last $30 \mathrm{~m}$ sprint, subjectsparticipants rested for $5 \mathrm{~min}$ before performing the RSA test and they were verbally instructed to provide maximum effort during the test. Blood samples were collected before and after the RSA test,. RSA performance (i.e., From the distance recorded in each sprint, best sprint and total distance,-) and fatigue index were recorded during each test session, and ratings of perceived exertion (RPE) and feeling scale (FS) were also-assessed after theeach RSA test. SubjectsParticipants were asked to maintain their usual sleeping habits, with a minimum of $7 \mathrm{~h}$ of sleep the night preceding each test session. They were instructed to use the same footwear in all sessions, to maintain their habitual physical activity while-and to avoiding strenuous exercise during the $24 \mathrm{~h}$ before the testing sessions. They were also advised to ingest a standardized meal at least $4 \mathrm{~h}$ before theeach test sessions, as recommended by Bougard et al. ${ }^{29}$, to avoid the effects of postprandial thermogenesis. The geographical proximity (i.e., Sfax, Tunisia) of the AT and NG provided similar climatic conditions (temperature: $18-22^{\circ} \mathrm{C}$, humidity: $40-46 \%$ and precipitation: $19 \mathrm{~mm}$ during February) in all tests. 
RSA test

158

159

160

161

162

163

164

165

166

167

168

169

170

171

172

173

174

175

176

177

178

179

As described by Boukhris et al. ${ }^{30}$, the RSA testing consisted of six repetitions of a $30 \mathrm{~s}$ maximal shuttle sprint over $5 \mathrm{~m}, 10 \mathrm{~m}, 15 \mathrm{~m}$ and $20 \mathrm{~m}$ alternatively (Figure 1), interspersed by a recovery period of $35 \mathrm{~s} .{ }^{31}$ During each recovery period, the subject returned to the starting position.Total and the- Distance covered during the $30 \mathrm{~s}$ bout was recorded to the closest $1 \mathrm{~m}$ using a measuring tape. ${ }^{31}$ Subsequently, peak (highest distance covered during one of the six $30 \mathrm{~s}$ bouts) and total (total distance covered during the six $30 \mathrm{~s}$ bouts) distances covered, as well as and the percentage decline of performance $(\% \mathrm{Dec})$ from the first to the last repetition $(\% \mathrm{Dec})$ and the difference between the best and the worst sprint distance (\%Diff) during the RSA were calculated. ${ }^{31}$ The \%Diff was used as a fatigue index, as suggested by Spencer et al. ${ }^{21}$

\section{Ratings of Perceived Exertion (RPE)}

SubjectsParticipants estimated their subjective exertion rating using the RPE scale. were presented with an RPE scale to provide a subjective exertion rating for the RSA test. The RPE scale consisted of a 15-point scale ranging from 6 (no exertion) to 20 (maximal exertion). The RPE scale is a reliable indicator of physical discomfort, has robust psychometric properties, and is strongly correlated with several other objective physiological measures of exertion. ${ }^{32}$

\section{Feeling Scale (FS)}

To measure differences in feelings of pleasure and displeasure experienced during exercise, the single-item Feeling Scale $(\mathrm{FS})^{33}$ was used. The scale is presented on an 11-point continuum from -5 to +5 with negative responses indicating unpleasurable feelings, and positive responses suggesting pleasurable feelings and 0 corresponding to "neutral" feelings. The simplicity of the scale allows for quick administration at multiple time points during and 
after exercise and provides a global sense of affect; but is unable to characterize specific mood states. ${ }^{33}$

\section{Blood sampling and analysis}

Blood samples were collected from a forearm vein before (after 5 min of seated rest), and 3-5 min after the RSA test on both the AT and NG sessions. Samples were placed in an ice bath and centrifuged immediately at $3000 \mathrm{rpm}$ and $4^{\circ} \mathrm{C}$ for $10 \mathrm{~min}$. Aliquots of the separated plasma were stored at $-80^{\circ} \mathrm{C}$ until analysis. To eliminate inter-assay variance, all samples were analyzed in the same assay run. All assays were performed in duplicate in the same laboratory with simultaneous use of a control serum from Randox. Hematological parameters (i.e., neutrophils (NEU), Lymphøcytes (LYM) and Monøcytes (MON)) were performed within $3 \mathrm{~h}$ in a multichannel automated blood cell analyzer [Beckman Coulter Gen system-2 (Coulter T540, Germany)]. Plasma glucose (GLC), Lactate Lac, muscle damage markers (i.e., ereatinine kinase (CK) and lactate dehydrogenase (LDH))and CRP were determined spectrophotometrically using an Architect Ci-4100-ABBOTT analyser (Abbott Deutschland, Wiesbaden, Germany). ${ }^{21} \mathrm{CK}, \mathrm{LDH}$ and CRP were respectively measured with the N-acetyl-Lcysteine method, the oxidation of Lacłactate to pyruvate method and the immunoturbidimetric method. The intra-assay coefficients of variation for these parameters kit-were $1.3 \%, 0.2 \%$ and $1.16 \%$, respectvely. ${ }^{21}$

\section{Statistical analysis}

All statistical tests were completedusing STATISTICA 10.0 Software (Stat-Soft, MaisonsAlfort, France). Normality of distribution was confirmed using the Shapiro-Wilks W-test. Paired-samples $t$-tests were used to analyze the effect of surface (AT vs. NG) on best performance and total distance, \%Dec, \%Diff, RPE and FS. To analyze the effect of surface on distance covered during the six repetitions of the RSA test, a two-way repeated-measures ANOVA [surface: 2 levels $(\mathrm{AT}$ and $\mathrm{NG}) \times$ sprint-block: 6 levels] was used. To analyze the 
205 effect of surface on the acute blood marker responses (pre-post values) during the RSA test, a 206 two-way repeated-measures ANOVA [surface: 2 levels $($ AT and NG) $\times$ time: 2 levels $($ Pre

207 and Post)] was used. Tukey's honest significance difference post-hoc tests were conducted to determine the origin of significance when a significant main or interaction effects were $F$-ratio was observed using Tukey's honest significance difference (HSD).Effect sizes were calculated as partial eta-squared $\left(\eta_{\mathrm{p}}{ }^{2}\right)$ for the $\Lambda$ NOV $\Lambda$ analysis and as Cohen's $d$ for the paired sample $t$ tests. Effect size (ES) was calculated to determine the magnitude of the change score and was interpreted using the following criteria: $<0.2=$ trivial, $0.2-0.6=$ small, $0.6-1.2=$ moderate, 1.2-2.0 $=$ large, and $>2.0=$ very large. ${ }^{34}$ Confidence intervals (CI 95\%) for ES were also specified. Data are presented as mean $\pm \mathrm{SD}$ and statistical significance was set at $\mathrm{p}<0.05$. All statistical tests were completed using STATISTICA 10.0 Software (Stat-Soft, Maisons-Alfort, France).

\section{Results}

\section{RSA performance, RPE and feeling scale}

There was a significant main effect for RSA sprint block $\left(F=11.43, p=0.001, \eta_{p}{ }^{2}=0.62\right)$ with lower performance distance covered registered in the last sprint block compared to the first sprint block on both AT $[($ rate of decrease $=-11 \pm 3 \%$, ES $=-1.97,95 \%$ CI $(-2.94$ to -0.83$)]$ and NG [(rate of decrease $=-15 \pm 4 \%, E S=-1.66,95 \%$ CI (-2.60 to -0.59$)]$ (Figure 1). In addition, there was a main effect for surface on RSA performance $\left(F=8.34, p=0.03, \eta_{p}{ }^{2}=0.54\right)$ with a higher RSA performance on AT compared to NG only during the last three sprint blocks (i.e., 4-6) $[(\mathrm{p}=0.009 ; \mathrm{ES}=0.91,95 \% \mathrm{CI}(-0.05$ to 1.79$) ; \mathrm{ES}=0.84,95 \% \mathrm{CI}(-0.10$ to 1.72$)$ and $\mathrm{ES}=0.63,95 \%$ CI (-0.30 to 1.50$)$, respectively)] (Figure 2). Similarly, a significant betweensurface effect was observed in the total distance covered $(\mathrm{t}(8)=2.95, \mathrm{p}=0.018, \mathrm{ES}=1.15,95 \%$ CI $95 \%(0.16$ to $2.04, d=1.12)$ with higher $(+6 \pm 2 \%)$ distance covered on the AT (Figure 3$)$ compared to NG. There was no significant difference between AT and NG for best 
230

231

232

233

performance distance covered and fatigue index $(\mathrm{p}>0.05)$ (Figure 3$)$. A significant betweensurface effect was observed for RPE $[(\mathrm{t}(8)=-2.31, \mathrm{p}=0.04, \mathrm{ES}=-0.49,95 \%$ CI $(-1.36$ to $0.42 \mathrm{~d}=0.50)]$ and FS $[(\mathrm{t}(8)=2.82, \mathrm{p}=0.02, \mathrm{ES}=0.81,95 \% \mathrm{CI} \quad(-0.13$ to $1.69 \mathrm{~d}=0.83)]$ with

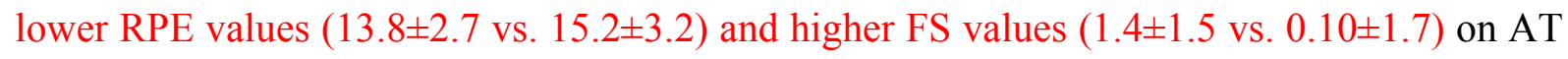
compared to NG. (Table 1).

\section{Physiologicallnflammatory, immune and muscle damage responses}

There was a significant main effect for time for muscle damage parameters $(\mathrm{F}=77.7$, $\mathrm{p}=0.0006 \mathrm{n}_{\mathrm{p}}{ }^{2}=0.9$ for $\mathrm{CK}$ and $\mathrm{F}=24.8, \mathrm{p}=0.0008, \mathrm{n}_{\mathrm{p}}{ }^{2}=0.8$ for $\mathrm{LDH}$, Figure 4), immune responses $\left(\mathrm{F}=26.4, \mathrm{p}=0.0007, \eta_{\mathrm{p}}{ }^{2}=0.87\right.$ for $\mathrm{NEU}, \mathrm{F}=113.1, \mathrm{p}=0.0004, \eta_{\mathrm{p}}{ }^{2}=0.93$ for $\mathrm{LYM}$ and $\mathrm{F}=12.33, \mathrm{p}=0.0009 \eta_{\mathrm{p}}{ }^{2}=0.61$ for MON $), \operatorname{Lac}\left(\mathrm{F}=908, \mathrm{p}=0.0008, \eta_{\mathrm{p}}{ }^{2}=0.97\right)$ and CRP $(\mathrm{F}=12.5$, $\left.p=0.007, \eta_{p}{ }^{2}=0.6\right)$; but no effect for GLC ( $>>0.05$ ) (Figure 5). CK, LDH, Lac, NEU and LYM increased immediately after the RSA test $(\mathrm{p}=0.001)$ on both AT [(ES=0.31, 95\% CI $(-0.58$ to 1.18); $\mathrm{ES}=0.91,95 \% \mathrm{CI}(-0.04$ to 1.79$)$; $\mathrm{ES}=6.98,95 \% \mathrm{CI}(4.44$ to 8.94$) ; \mathrm{ES}=0.61,95 \% \mathrm{CI}$ (-0.36 to 1.52$)$ and $\mathrm{ES}=1.77,95 \% \mathrm{CI}(0.61$ to 2.77$)$, respectively) $]$ and $\mathrm{NG}[(\mathrm{ES}=0.25,95 \%$ CI (-0.64 to 1.12$) ; \mathrm{ES}=0.69,95 \% \mathrm{CI}(-0.24$ to 1.56$) ; \mathrm{ES}=5.15,95 \% \mathrm{CI}(3.17$ to 6.69$)$; $\mathrm{ES}=0.96,95 \% \mathrm{CI}(-0.06$ to 1.88$)$ and $\mathrm{ES}=3.56,95 \% \mathrm{CI}$ (1.95 to 4.83), respectively)], while CRP and MON increased only on AT $[(\mathrm{p}=0.0007, \mathrm{ES}=0.20,95 \% \mathrm{CI}(-0.74$ to 1.11$)$ for CRP and $\mathrm{p}=0.02, \mathrm{ES}=1.7,95 \% \mathrm{CI}(0.57$ to 2.70$)$ for $\mathrm{MON})]$. Concerning differences between playing surfaces, Lac, Neu and LYM were higher following the RSA test on NG compared to $\mathrm{AT}[\mathrm{p}=0.03 ; \mathrm{ES}=-0.80,95 \% \mathrm{CI}(-1.67,0.14) ; \mathrm{ES}=-0.16,95 \% \mathrm{CI}(-1.03,0.72)$ and $\mathrm{ES}=-0.94$, 95\% CI (-1.82, 0.02), respectively)], with no post-RSA test differences between AT and NG for the other blood biomarkers $(\mathrm{p}>0.05)$.

\section{Discussion}

The present study was designed to examine the effect of playing surface (NT vs. AT) on physical performance, RPE, FS and acute physiological responses to a RSA test. The main 
255 finding from this study is an improved physical performance on AT compared to NG, as evidenced by a higher total distance covered and lower decrement in RSA performance on AT. This improved RSA performance on AT was accompanied by improved perceptual (i.e., lower RPE scores and higher FS values) and enhancements in some physiological (i.e., lower Lac, Neu and LYM) biomarkers. These findings: 1) suggest that AT might elicit improved physical performance compared to $\mathrm{NG}$; 2) improve understanding of the mechanisms which influence RSA performance on different playing surfaces; and 3) support the utilization of AT as a playing surface for football matches ${ }^{8}$

improved The main finding of the current study was that the decline in RSA was blunted on AT compared to NG. byimproved perceptual (RPE and FS) and some blood biochemistry (Lac, Neu and LYM) responses. These findings of enhanced RSA on ATand might help have implications for.

The influence of playing surface on certain components of football performance is equivocal. ${ }^{3}$ While the majority of previous studies have reported similar straight-line sprint performances (e.g., distance covered and speed) on AT compared to $\mathrm{NG}, 11,12,14$ it appears that performance tasks incorporating greater reliance on agility and change of direction ability are more likely to be enhanced on AT compared to NG.11,12,35 In the present study, where the RSA test comprised repeated maximal shuttle sprints including both straight-line sprint and direction change abilities, total distance covered (but not best distance covered performance,) was enhanced on AT compared to NG. These results suggest that physical performance in during a RSA test is more likely to be enhanced on AT when such tests place greater reliance on require greater change of direction and agility capabilities, and might help improve understanding of the previous inter-study disparities when assessing the influence of playing surface type on physical performance. ${ }^{11,12,14}$ 
In addition to best sprint and the total distance covered in during a RSA test, the decline in maximal sprint in physical performance through the match has also been identified as a determinant of football performance. ${ }^{36}$ Therefore, recent studies have assessed the decline in physical performance during repeated sprint bouts ${ }^{12-14}$ performed on different playing surfaces. Although RSA declined on both AT and NG in the present study, this decline in RSA was blunted on AT. This observation conflicts with findings by Hughes et al. ${ }^{12}$ and López-Fernández et al. ${ }^{14}$ who reported that the decline in RSA performance was similar on AT and NG, but is consistent with findings by Stone et al. ${ }^{13}$ who observed an attenuated decline in RSA performance on AT compared to NG. These inter-study disparities might be linked to differences in the quality of the pitches used, as outlined previously. ${ }^{7,13}$ Indeed, it has been suggested that high quality NG surfaces, which meet the criteria of FIFA's highest rating "FIFA 2 Star", offers a more comparable mechanical behavior to AT. Consequently, this results in a more homogenous physical and perceptual strain between AT and NG such that between-surface effects on physical performance are less likely. ${ }^{12,14}$ Conversely, lower quality NG pitches, classified as "FIFA 1 Star", can alter the movement mechanics of locomotor muscles and, by extension, the amount of work performeddone ${ }^{37}$ compared to AT. This would be expected to translate into a greater physical performance disparity between NG and AT. ${ }^{13,38}$ This might account for enhanced RSA performance observed in the present study on AT compared to NG, which only attained a "FIFA 1 Star" rating, and the previous studies which reported similar RSA on AT and NG when utilizing a "FIFA 2 Star" rated NG playingsurface. ${ }^{12-14}$

It is recognized that AT and NG can exhibit different stiffness characteristics. ${ }^{39}$ Such intersurface differences could acutely alter the movement mechanies of the locomotor muscles and, by extension, the amount of work done, ${ }^{25}$ and amount of eccentric stress, muscle damage and physiological strain experienced during soccer activity on these disparate playing 
surfaces. ${ }^{38-41}$ In the present study, blood Lac, NEU and LYM responses were lower on AT compared to $\mathrm{NG}_{\text {; }}$ with no-differences in $\mathrm{CK}, \mathrm{CRP}$, MON, GLC and $\mathrm{LDH}$, compared to NG. These observations provide some evidence to suggest that the degree of physiological strain might be attenuated on AT compared to NG.

In the current study, RPE was lower and FS response was higher during the RSA test performed on AT compared to NG. This blunting in physical discomfort perception and the reporting of more pleasurable feelings on AT compared to NG might have contributed to the enhanced RSA test-performance on AT. Although this improved perceptual response might have been linked to the lower physiological strain on AT, we cannot exclude the possibility that a more positive perceptual response on AT might have been linked to higher player satisfaction and better overall image impression of AT compared to NG. ${ }^{42}$ Indeed, several researchers have documented higher user satisfaction and better user impression on AT compared with $\mathrm{NG}^{43}$ with the first impression usually visual (i.e., overall image of the playing surface) ${ }^{42}$ However, the present observations conflict with those of Andersson et al. ${ }^{10}$, who reported that players perceive football activity to be more physically demanding on AT than those on NG, and Stone et al. ${ }^{13}$ who reported that participants generally reported no difference in RPE between surfaces. Therefore, while the improved RSA performance on AT compared to NG in the current study might be linked to enhancements in aspects of physiological and perceptual responses during the RSA test, further research is required to resolve the underlying mechanisms for this surface-type-dependent effect on RSA.

The results of the present study indicated an improvement in physical performance and some physiological and perceptual responses on a $3^{\text {rd }}$ generation AT compared to NG in subjects who were not accustomed to regularly training or playing on AT. Therefore, regularly training on AT might have implications for eliciting greater training adaptations. ${ }^{28}$ However, further research is required to investigate the effect of playing surface on more physiological 
responses (e.g., muscle damage, inflammation, oxidative stress, metabolic demands, heart rate etc.) in groups of subjects accustomed and unaccustomed to regularly training on AT.

\section{Practical Applications}

The current study indicated that physical, physiological and perceptual markers during a RSA test, which incorporated multiple direction changes, was better on AT compared to NG. This is the first study to evaluate different physiological responses (i.e., inflammation, muscle damage, immune function) to RSA test performed on third-generation AT compared to NG.The data show that the decline in RSA was blunted on AT compared to the NG. The improved RSA performance on AT was accompanied by improved perceptual (RPE and FS) and some blood biochemistry (Lac, Neu and LYM) responses. Accordingly, the present observations support the use of AT for training and matches, as already recommended by sport governing bodies, as this surface might elicit superior performance compared to a traditional NG surface. Therefore, the original observations of the current study might have important implications for team sport performance on different playing surfaces.

\section{Conclusion}

This study evaluated physical performance and different physiological (i.e., inflammation, muscle damage, immune function) and perceptual (RPE and FS) responses to a RSA test performed on a $3^{\text {rd }}$ generation AT and a FIFA 1 Star rated NG. The findings indicate that the decline in RSA performance was blunted on AT compared to NG. The improved physical performance on AT was accompanied by improved perceptual and some blood biochemistry (Lac, Neu and LYM) responses. Sprinting performance in an RSA test, which incorporated multiple direction changes, was better on $\mathrm{AT}$ compared to NG in the current study.Although the underlying mechanisms for the surface-type-dependent effect on RSA ability performance is not entirely clear, the results of the present study suggest that improved RSA on AT might 
353 be a function of enhancements in certain perceptual (lower RPE and most positive feelings)

354 and physiological (lower blood Lac,NEU and LYM) responses. These observations might have implications for team sport performance on different playing surfaces.

\section{Acknowledgements}

359 The authors wish to thank all the participants for their maximal effort and cooperation.

\section{Declaration of Interest}

361 The authors report no conflicts of interest, no relevant disclosures and no external financial

362 support. The authors alone are responsible for the content and writing of the paper. 


\section{References}

1. Morcillo, JA, Jimenez-Reyes P, Cuadrado-Penafiel V et al. Relationships between repeated sprint ability, mechanical parameters, and blood metabolites in professional soccer players. J Strength Cond Res. 2015; 29(6), 1673-1682.

2. Sterzing T, Muller C, Hennig EM et al. Actual and perceived running performance in soccer shoes: A series of eight studies. Footwear Sci. 2009; 1: 5-17

3. Rago V, Silva JR, Brito J et al. Switching between pitch surfaces: practical applications and future perspectives for soccer training. J Sports Med Phys Fitness 2018. doi: 10.23736/S0022-4707.18.08278-6.

4. Brito J, Krustrup P, Rebelo A. The influence of the playing surface on the exercise intensity of small-sided recreational soccer games. Hum Mov Sci. 2012; 31(4), 946-956.

5. UEFA. FIFA quality concept: Handbook of test methods and requirements for artificial turf football surfaces, Nyon, Switzerland: UEFA, 2005.

6. Burillo P, Gallardo L, Felipe JL, et al. Mechanical assessment of artificial turf football pitches: The consequences of no quality certification. Sci Res Essays 2012; 7(28):24572465

7. Sánchez-Sánchez J, García-Unanue J, Jiménez-Reyes $\mathrm{P}$, et al. Influence of the Mechanical Properties of Third-Generation Artificial Turf Systems on Soccer Players' Physiological and Physical Performance and Their Perceptions. PloS One. 2014; 9(10):111.

8. FIFA. FIFA Quality Programme for Football Turf. Handbook of Test Methods. Zurich: FIFA; 2015.

9. Kanaras V, Metaxas TI, Mandroukas A, et al. The Effect of Natural and Artificial Grass on Sprinting Performance in Young Soccer Players. American Journal of Sports Science $2014 ; 2(1): 1-4$. 
10. Andersson H, Ekblom B, Krustrup P. Elite football on artificial turf versus natural grass: Movement patterns, technical standards, and player impressions. J Sports Sci. 2008; 26(2):113-122.

11. Gains GL, Swedenhjelm AN, Mayhew JL, et al. Comparison of speed and agility performance of college football players on field turf and natural grass. J Strength Cond Res 2010; 24:2613-2617.

12. Hughes MG, Birdsey L, Meyers RW, et al. The effect of playing surface on physiological responses and performance variables in a controlled football simulation. J Sports Sci $2013 ; 31: 878-886$.

13. Stone KJ, Hughes MG, Stembridge MR, et al. The influence of playing surface on physiological and performance responses during and after soccer simulation. Eur J Sport Sci 2014;16(1):42-49.

14. López-Fernández J, García-Unanue J, Sánchez-Sánchez J, et al. Neuromuscular responses and physiological patterns during a soccer simulation protocol. Artificial turf versus natural grass. J Sports Med Phys Fitness. 2018; 58(11):1602-1610

15. Rago V, Rebelo AN, Pizzuto F et al. Small-sided soccer games on sand are more physically demanding but less technically specific compared to games on artificial turf. $J$ Sports Med Phys Fitness. 2018; 58(4), 385-391.

16. Di Michele R, Di Renzo AM, Ammazzalorso S, et al. Comparison of physiological responses to an incremental running test on treadmill, natural grass, and synthetic turf in young soccer players. $J$ Strength Cond Res. 2009; 23: 939- 945.

17. Sassi A, Stefanescu A, Menaspa $\mathrm{P}$, et al. The cost of running on natural grass and artificial turf surfaces. J Strength Cond Res 2011; 25:606-611.

18. Cobley JN, Close GL, Bailey DM, et al. Exercise redox biochemistry: Conceptual, methodological and technical recommendations. Redox Biol. 2017; 12 :540-548. 
19. Brancaccio P, Giuseppe L, Nicola M. Biochemical markers of muscular damage. Clinical Chemistry and Laboratory Medicine. 2010; 48, 757-767.

20. Ammar A, Chtourou H, Hammouda O, et al. Relationship between biomarkers of muscle damage and redox status in response to a weightlifting training session: Effect of time-ofday. Physiol Int. 2016; 103(2):243-261

21. Ammar A, Chtourou H, Trabelsi K, et al. Temporal specificity of training: intra-day effects on biochemical responses and Olympic-Weightlifting performances. J Sports Sci $2015 ; 33(4): 358-68$.

22. Ammar A, Chtourou H, Bailey SJ, Hoekelmann A, Souissi N. Effects of pomegranate supplementation on exercise performance and post-exercise recovery: A systematic review. Brit J Nutr 2018; 20(11):1201-1216.

23. Main LC, Dawson B, Heel K, et al. Relationship between inflammatory cytokines and self-report measures of training overload. Research in Sports Medicine. 2010; 18, $127-$ 139.

24. Ammar A, Turki M, Chtourou H, et al. Pomegranate Supplementation Accelerates Recovery of Muscle Damage and Soreness and Inflammatory Markers after a Weightlifting Training Session. PLoS One. 2016; 11(10): e0160305

25. Romdhani M, Hammouda O, Chaabouni Y, et al. Sleep deprivation affects post-lunch dip performances, biomarkers of muscle damage and antioxidant status. Biol Sport. 2018; 36(1):55-65.

26. Hammouda O, Chtourou H, Chaouachi A, et al. Time-ofday effects on biochemical responses to soccer-specific endurance in elite Tunisian football players. J Sports Sci 2013; 31:963-971.

27. Ammar A, Chtourou H, Souissi N. Effect of time-of-day on biochemical markers in response to physical exercise. J Strength Cond Res 2016; 31(1):272-282 
28. Binnie MJ, Dawson B, Pinnington $\mathrm{H}$, et al. Effect of training surface on acute physiological responses after interval training. J Strength Cond Res. 2013 ;27(4):104756.

29. Bougard C, Moussay S, Gauthier A, et al. Effects of waking time and breakfast intake prior to evaluation of psychomotor performance in the early morning. Chronobiol Int $2009 ; 26,324-336$.

30. Boukhris O, Hsouna H, Chtourou L, et al. Effect of Ramadan fasting on feelings, dietary intake, rating of perceived exertion and repeated high intensity short-term maximal performance. Chronobiol Int. 2018; 12:1-10.

31. Boddington MK, Lambert MI, St Clair Gibson A, et al. Reliability of a 5-m multiple shuttle test. J Sports Sci2001;19(3):223-228

Spencer MD, Bishop D, Dawson B, et al. Physiological and metabolic responses of repeated-sprint activities. Sports Med 2005; 35: 1025-1044

32. Borg GA. Psychophysical bases of perceived exertion. Med Sci Sports Exerc 1982; 14:377-381.

33. Hardy CJ, Rejeski WJ. Not what, but how one feels: The measurement of affect during exercise. J Sport Exerc Psychol 1989; 11:304-317.

34. Hopkins WG. A scale of magnitudes for effect statistics. Sport science. 2012; Retrieved from http://sportsci.org/resource/stats/index.html

35. Fletcher N, Nokes L, Hughes MG, et al. Physiology - Effects of playing surface in football activity. Turf Roots Magazine 2009; 3:41-44.

36. Rampinini E, Bishop D, Marcora S M et al. Validity of simple field tests as indicators of match-related physical performance in top-level professional soccer players. Int J Sports Med. 2007; 28(3), 228-235. 
37. Ferris DP, Louie M, Farley CT. Running in the real world: Adjusting leg stiffness for different surfaces. Proc Biol Sci1998 ; 265 :989- 994.

38. Glaister M. (2005). Multiple sprint work - Physiological responses, mechanisms of fatigue and the influence of aerobic fitness. Sports Medicine 2005 ; 35 :757-777.

39. Naunheim R, Parrott H, Standeven, J. (2004). A comparison of artificial turf. J Trauma $2004 ; 57: 1311-1314$.

40. Greig M, Siegler JC. Soccer-specific fatigue and eccentric hamstrings muscle strength. Journal of Athletic Training2009, 44, 180-184.

41. Nosaka K, Newton M, Sacco P. Delayed-onset muscle soreness does not reflect the magnitude of eccentric exercise-induced muscle damage. Scand J Med Sci Sports 2002; $12: 337-346$.

42. Burillo P, Gallardo L, Felipe JL et al. Artificial turf surfaces: Perception of safety, sporting feature, satisfaction and preference of football users. Eur J Sport Sci. 2014; 14:1, $437-447$

43. Zanetti EM. Amateur football game on artificial turf: Players' perceptions. Applied Ergonomics. 2009; 40(3), 485_490. 


\section{Figure Captions}

504

Figure 1: Schematic representation of repeated sprint ability test

506

507

Figure 2: Effect of surface-types on distancecovered during each $30 \mathrm{~s}$ block in the repeatedsprint ability test.

509

*: difference between artificial turf (AT) and natural grass (NG) with $\mathrm{p}<0.05$

510

511

512

513

514

Figure 3: Effect of surface-types on best performance, total covered distance and fatigue index during the repeated-sprint ability test.

*: difference between artificial turf (AT) and natural grass (NG)with $\mathrm{p}<0.05$

Figure 4: Effect of surface-typeon muscle damage biomarkers [creatine kinase (CK) and lactate dehydrogenase $(\mathrm{LDH})]$ before and after the repeated-sprint ability test.

$\$$ : difference compared to pre-test with $\mathrm{p}<0.05$

Figure 5: Effect of surface-types on blood lactate (Lac), C - reactive protein (CRP), glucose 529 (GLC), neutrophils (NEU), lymphocytes (LYM) and monocytes (MON).

530 \$: difference compared to pre-test with $\mathrm{p}<0.05$

$531 *$ : difference between artificial turf (AT) and natural grass (NG) with $\mathrm{p}<0.05$ 


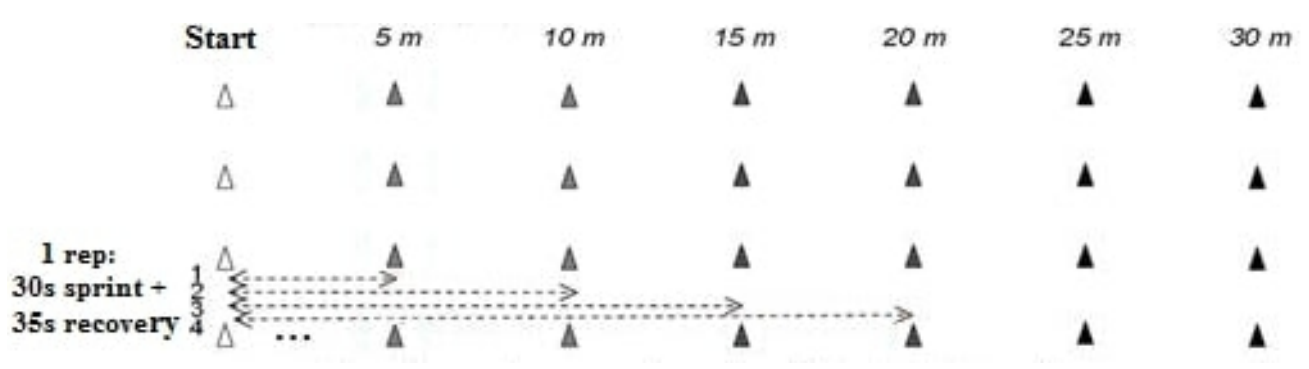

Figure 1: Schematic representation of repeated sprint ability test

$179 \times 46 \mathrm{~mm}(72 \times 72 \mathrm{DPI})$ 


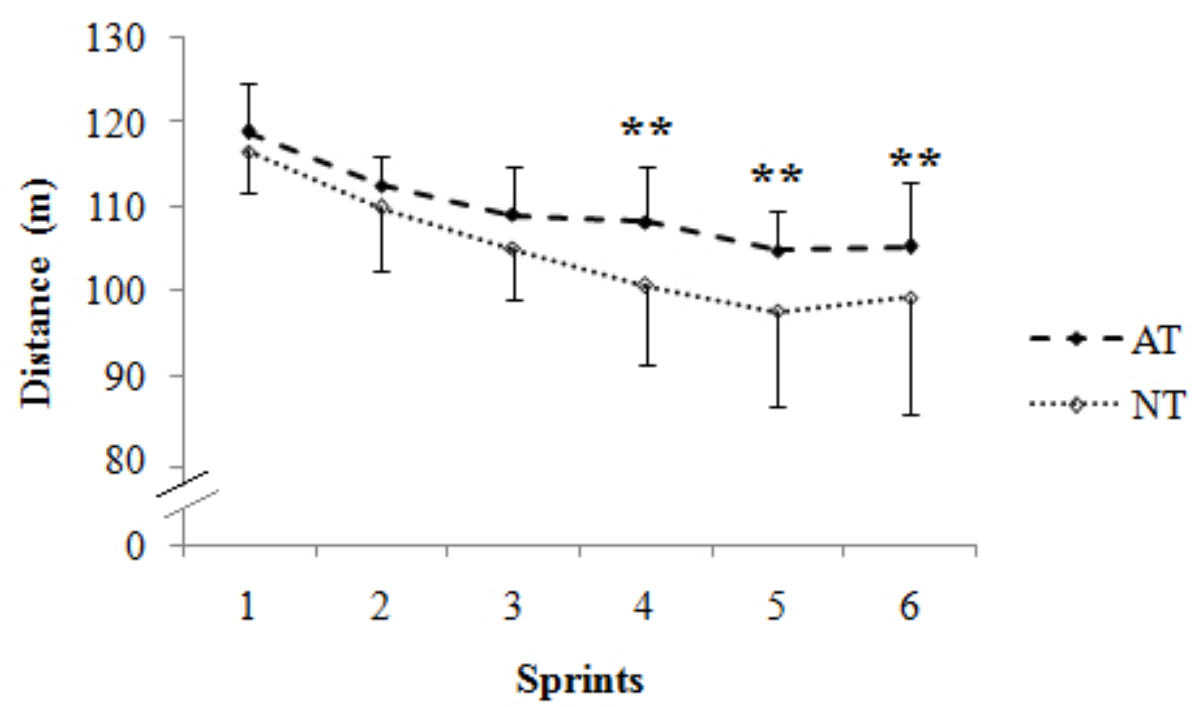

Figure 2: Effect of surface-types on distancecovered during each $30 \mathrm{~s}$ block in the repeated-sprint ability test.

*: difference between artificial turf (AT) and natural grass (NG) with $p<0.05$

$122 \times 73 \mathrm{~mm}(96 \times 96 \mathrm{DPI})$ 


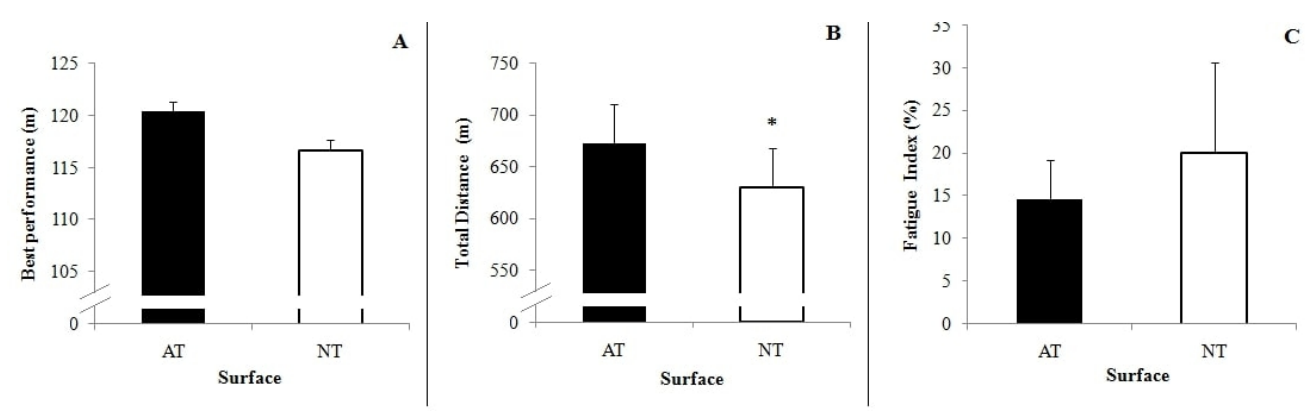

Figure 3: Effect of surface-types on best performance, total covered distance and fatigue index during the repeated-sprint ability test.

*: difference between artificial turf (AT) and natural grass (NG)with $p<0.05$

$385 \times 115 \mathrm{~mm}(72 \times 72 \mathrm{DPI})$ 

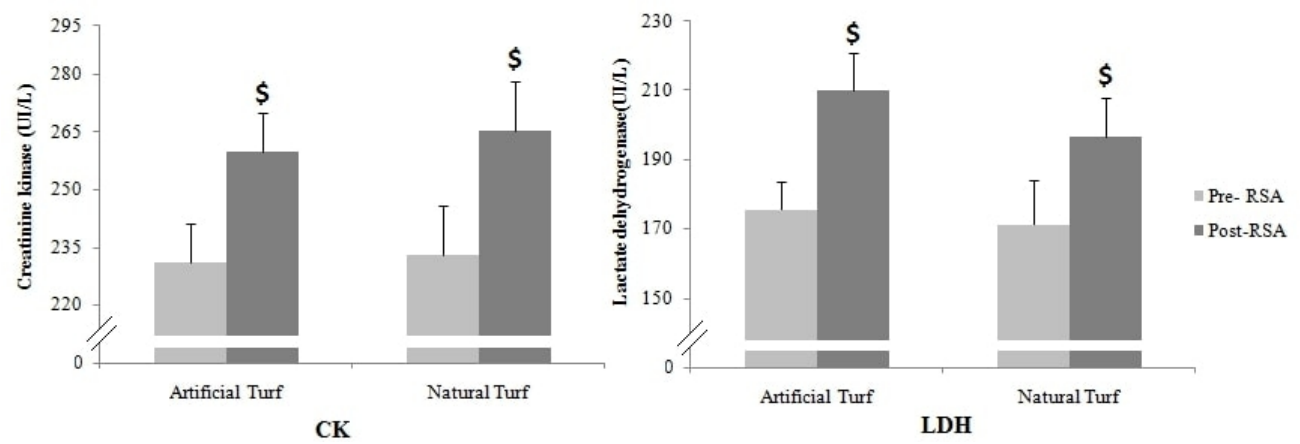

Figure 4: Effect of surface-typeon muscle damage biomarkers [creatine kinase (CK) and lactate dehydrogenase $(\mathrm{LDH})]$ before and after the repeated-sprint ability test.

$\$$ : difference compared to pre-test with $\mathrm{p}<0.05$

$305 \times 110 \mathrm{~mm}(72 \times 72$ DPI) 

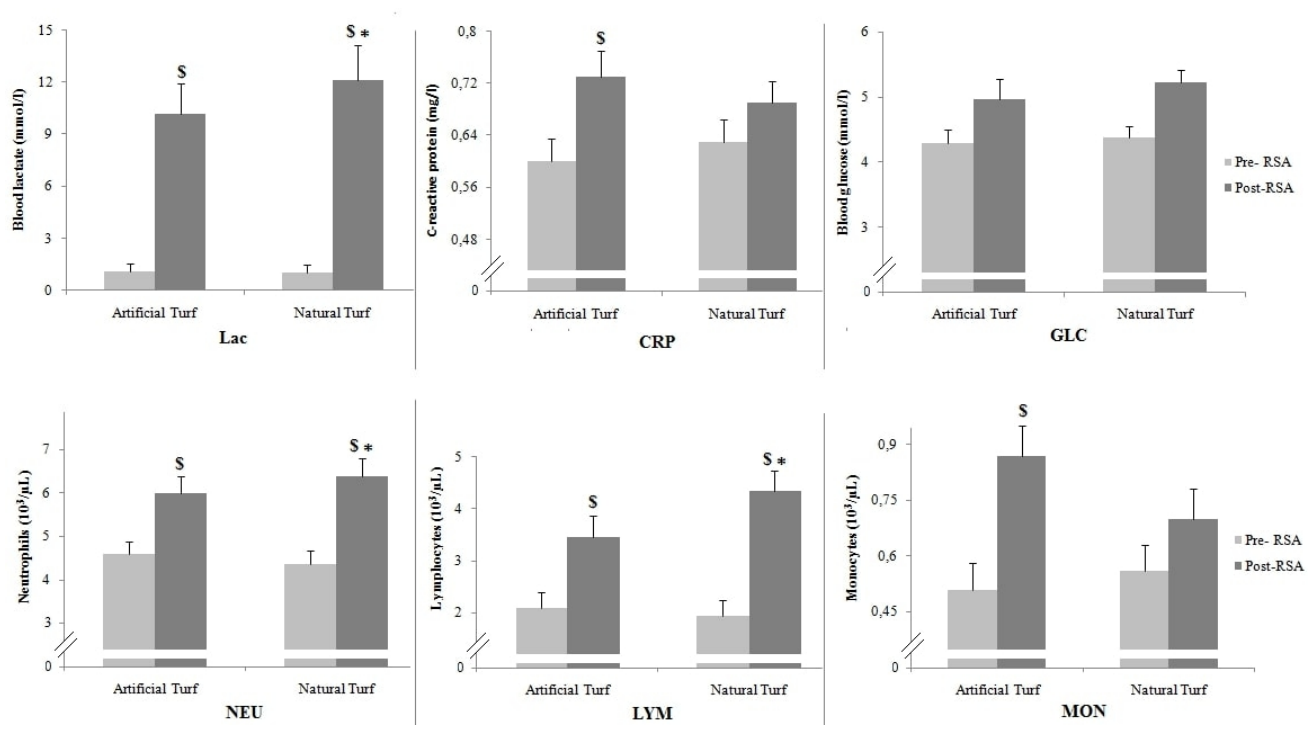

Figure 5: Effect of surface-types on blood lactate (Lac), C - reactive protein (CRP), glucose (GLC), neutrophils (NEU), lymphocytes (LYM) and monocytes (MON).

$\$$ : difference compared to pre-test with $\mathrm{p}<0.05$

*: difference between artificial turf (AT) and natural grass (NG) with $p<0.05$

$408 \times 224 \mathrm{~mm}(72 \times 72 \mathrm{DPI})$ 